\title{
Stressor Controllability Modulates Stress-Induced Dopamine and Serotonin Efflux and Morphine-Induced Serotonin Efflux in the Medial Prefrontal Cortex
}

\author{
Sondra T Bland*,', David Hargrave', Julie L Pepin', Jose Amat', Linda R Watkins' and Steven F Maier' \\ 'Department of Psychology, Center for Neuroscience, University of Colorado, Boulder, CO, USA
}

\begin{abstract}
It has previously been shown that inescapable (IS) but not escapable (ES) stress potentiates the rewarding properties of morphine as measured by conditioned place preference and psychomotor activation, and that this potentiation may be mediated by dorsal raphe nucleus (DRN) serotonin (5-HT) neurons. The medial prefrontal cortex (mPFC) has been implicated in both reward and stress, and is a projection region of the DRN. The mPFC also contains dopaminergic afferents from the ventral tegmental area, which has been the focus of many studies exploring both the rewarding properties of drugs and the aversive properties of stress. The role of the mPFC in stress/ drug reactivity interactions is largely unknown. The present study usedin vivo microdialysis to examine 5-HT and dopamine (DA) efflux in the $\mathrm{MPFC}$ of rats during IS, ES or no stress (NS). IS and ES rats received the stressor in yoked pairs. The stressor consisted of tailshocks that could be terminated for both rats by the ES rats. Large increases in 5-HT and DA levels were observed during IS but not ES or NS. DA and $5-H T$ efflux were also measured $24 \mathrm{~h}$ later in the same rats in response to morphine $(3 \mathrm{mg} / \mathrm{kg})$ or saline. Sustained increases in 5 HT levels were observed after morphine in rats that had previously received IS but not in rats that had received ES or NS. No changes in DA efflux were observed after morphine. Thus, 5-HT and DA in the MPFC may be involved in stressor controllability effects, and the sensitization of 5-HT neurons by IS extends to the mPFC and to morphine as a challenge.

Neuropsychopharmacology (2003) 28, 1589-1596, advance online publication, 28 May 2003; doi: I 0. I038/sj.npp. 1300206
\end{abstract}

Keywords: dopamine; serotonin; morphine; prefrontal cortex; stress

\section{INTRODUCTION}

There is currently a great deal of interest in the importance of stress as a risk factor for substance abuse and addiction (NIDA, 2002). Exposure to stressful experiences has been shown to be a powerful mediator of the response of an individual to drugs. Preclinical studies indicate that stress can potentiate the rewarding properties of addictive drugs (Shaham and Stewart, 1994), increase the rate of drug selfadministration (Goeders and Guerin, 1994; Piazza and Le Moal, 1998), and reinstate drug-seeking behavior (Shaham et al, 1996; Shalev et al, 2000).

Many of the behavioral consequences of stress can be modulated by stressor controllability. Exposure to an uncontrollable stressor, but not a controllable stressor, results in a wide variety of behavioral outcomes known as learned helplessness (Maier and Seligman, 1976). For example, exposure to inescapable shock (IS) but not equal

\footnotetext{
*Correspondence: Dr ST Bland, Department of Psychology, University of Colorado, Campus Box 345, Boulder, CO 80309-0345, USA,

Tel: + I 303492 3288, Fax: + I 303492 2967,

E-mail: blands@ucsu.colorado.edu

Received 20 January 2003; revised 03 March 2003; accepted 07 March 2003

Online publication: 21 March 2003 at http://www.acnp.org/citations/ Npp032103029/default.pdf
}

amounts and durations of escapable shock (ES) leads to later failure to learn to escape shocks in a different situation (Maier and Seligman, 1976). Other behavioral outcomes resulting from exposure to IS but not ES include an exaggeration of fear conditioning to a context (Maier et al, 1995), increases in neophobia (Minor et al, 1994), and reductions in social interaction (Short and Maier, 1993).

Activation and sensitization of serotonergic (5-HT) neurons in the dorsal raphe nucleus (DRN) is necessary for producing the behavioral effects of uncontrollable stress (Maier et al, 1995). Sensitization of DRN 5-HT neurons occurs because IS, relative to ES, selectively activates DRN 5-HT neurons (Grahn et al, 1999). This intense activation produces large amounts of extracellular 5-HT in projection regions of the DRN such as the basolateral amygdala (Amat et al, 1998a, b) as well as in the DRN itself (Amat et al, 2001; Maswood et al, 1998). 5-HT released within the DRN binds to inhibitory somatodendritic $5-\mathrm{HT}_{\mathrm{a}}$ receptors (Sotelo et al, 1990). Thus, DRN 5-HT neurons are under self-inhibition when activated. Because exposure to IS produces high concentrations of extracellular 5-HT in the DRN for a prolonged period of time (Maswood et al, 1998), IS might be expected to desensitize or downregulate DRN $5-\mathrm{HT}_{\mathrm{a}}$ receptors. Receptor binding experiments support this idea, revealing that IS, but not ES, reduces $5-\mathrm{HT} 1_{\mathrm{a}}$ receptor numbers for a number of days (Short, 1997). Since these 
receptors are inhibitory, this sensitizes these neurons, resulting in an exaggerated release of 5-HT in DRN projection regions during subsequent stimulation (Amat et al, 1998a).

In terms of interactions with drugs of abuse, exposure to IS has previously been shown to potentiate morphine's rewarding properties in an unusual fashion. Acute exposure to stressors in general has been shown to potentiate both drug self-administration and conditioned place preference (CPP) that occur immediately after stressor exposure and/or in the stressor environment (Goeders and Guerin, 1994; Piazza and Le Moal, 1998; Shaham et al, 1996; Shaham and Stewart, 1994, 1995; Shalev et al, 2000). However, Will et al (1998) reported that prior IS, but not ES, increased CPP to morphine, but not amphetamine, days after stressor exposure and in environments very different than the stressor environment. IS also potentiated the locomotor activating effects of morphine but not amphetamine in this fashion (Will et al, 2002). Will et al $(1998,2002)$ suggested that these results might have been a product of the interaction between the sensitization of DRN neurons selectively produced by IS and dopaminergic (DA) processes in either the nucleus accumbens (NAc) or the medial prefrontal cortex (mPFC). Serotonin in these structures can potentiate DA release (Rasmusson et al, 1994), and it is noteworthy that morphine activates DRN 5-HT neurons (Tao and Auerbach, 1994) but amphetamine does not (Rebec and Curtis, 1983). Given that IS sensitizes DRN 5-HT neurons, morphine might be expected to produce exaggerated extracellular levels of 5-HT in projection regions of the DRN such as the mPFC in subjects that had been previously exposed to IS, thereby potentiating DA levels in them and thus potentiating reward-related processes.

It is well established that the $\mathrm{mPFC}$ is responsive to stressors. Evidence for the responsiveness of mPFC monoamines to stressors includes the finding that conditioned fear results in increased levels of extracellular 5-HT in the mPFC (Hashimoto et al, 1999). The mPFC DA system is particularly sensitive to stress. This has been demonstrated by numerous microdialysis studies in which extracellular DA levels increased in the mPFC during exposure to diverse stressors (Davis et al, 1994; Finlay et al, 1995; Kawahara et al, 1999; Sorg and Kalivas, 1993; Sullivan and Gratton, 1998; Yoshioka et al, 1996).

Similarly, morphine-induced changes have been observed in the $\mathrm{mPFC}$. For example, morphine-induced reorganization in the prelimbic $(\mathrm{Cg} 3)$ region of the $\mathrm{mPFC}$ has been reported (Robinson and Kolb, 1999). The mPFC also appears to modulate morphine's rewarding properties as measured by CPP. In support of this, Tzschentke and Schmidt (1999) have found that lesions of the mPFC interfere with morphine CPP.

Little is known about the role of the MPFC in interactions between stress and drug reactivity. It is also not known whether stressors differing in their controllability would lead to different levels of extracellular 5-HT and DA in the mPFC. Prior studies have examined 5-HT only in the basolateral amygadala (Amat et al, 1998a), ventral hippocampus (Amat et al, 1998b), and periaqueductal gray (Amat et al, 1998b). In addition, the sensitivity of DA responses to stressor controllability is largely unexplored. The current study used in vivo microdialysis to examine 5-HT and DA levels in the mPFC during IS, ES, or no stress (NS) treatment. In addition, 5-HT and DA were measured in the same rats during a morphine or saline challenge $24 \mathrm{~h}$ after stressor treatment.

\section{MATERIALS AND METHODS}

\section{Subjects}

Adult male Harlan Sprague-Dawley rats (250-350 g) were used. Rats were housed two per cage on a $12 \mathrm{~h}$ light-dark cycle with food and water available ad libitum. Rats were allowed to acclimate to the colony for 1 week prior to experimentation. All experiments were conducted in accordance with protocols approved by the University of Colorado Animal Care and Use Committee.

\section{Surgery}

Surgery was performed 5-7 days before experimentation. Under halothane anesthesia, CMA 12 guide cannulae were aimed at either the right or the left $\mathrm{mPFC}(\mathrm{AP}=2.7$, $\mathrm{LM}= \pm 0.5, \mathrm{DV}=1.4$ from bregma) (Paxinos and Watson, 1998). The left or right hemisphere was counterbalanced by yoked cohort (IS, ES, and NS) so that rats in each cohort had cannulae in the same hemisphere. The guide cannulae were anchored to the skull with three jewelers screws and dental cement. Screw caps of $15 \mathrm{ml}$ Eppendorf tubes were also fastened to the cap with dental acrylic to protect the probes and connectors during the experiments. Rats were individually housed after surgery.

\section{Microdialysis}

On the afternoon before the experiment, rats were transferred to the dialysis room which was on the same light-dark cycle as the colony. Microdialysis probes (CMA $12,2 \mathrm{~mm}$ active membrane, $M_{\mathrm{r}}$ cutoff $\left.20000 \mathrm{Da}\right)$ were inserted into the guide cannulae and rats were placed separately in Plexiglas infusion bowls with food and water available. Ringers solution was perfused through the probes using a CMA infusion pump at a flow rate of $0.2 \mu \mathrm{l} / \mathrm{min}$ overnight. The next morning the flow rate was increased to $0.8 \mu \mathrm{l} / \mathrm{min}$ and after a $2 \mathrm{~h}$ equilibration period sampling was begun. Samples were collected every $20 \mathrm{~min}$ and immediately frozen at $-80^{\circ} \mathrm{C}$ until analyzed. After three basal samples were taken in the infusion bowls, the entire dialysis setup (which is self-contained on a wheeled cart) was moved into a separate shock room and rats were subjected to ES or IS as described below. We have previously demonstrated using microdialysis that restraint does not increase 5-HT efflux in the DRN (Maswood et al, 1998), amygdala (Amat et al, 1998a), or hippocampus (Amat et al, 1998b) to levels different from those during ES. Moreover, restraint does not potentiate morphine CPP using our paradigm (Will et al, 1998). Therefore, no shock controls (NS) but not restraint controls were used. NS rats remained in the original dialysis room throughout the experiment. Sampling continued throughout the entire duration of stress ( $100 \mathrm{~min})$. After termination of the shocks, the rats were placed back in the bowls and returned to the original room. Sampling continued for another $100 \mathrm{~min}$. The flow rate then reduced 
to $0.2 \mu \mathrm{l} / \mathrm{min}$ and rats remained in the dialysis room overnight. The next morning the flow rate was again increased to $0.8 \mu \mathrm{l} / \mathrm{min}$. After a $2 \mathrm{~h}$ equilibration period, sample collection began. Morphine sulfate was dissolved in sterile $0.9 \%$ saline at a concentration of $3 \mathrm{mg} / \mathrm{ml}$ for an injection volume of $1 \mathrm{ml} / \mathrm{kg}$. After three basal samples, either morphine $(3 \mathrm{mg} / \mathrm{kg})$ or saline $(1 \mathrm{ml} / \mathrm{kg})$ was injected subcutaneously, and samples were collected for $180 \mathrm{~min}$.

\section{Shock Controllability Procedure}

For both IS and ES exposure, each rat was placed in a Plexiglas box $(14 \times 11 \times 17 \mathrm{~cm})$ with a wheel mounted in the front and a Plexiglas rod extending out the back. The rats' tails were taped to the Plexiglas rod and affixed with copper electrodes. Rats received shocks in yoked pairs. One rat (ES) was in a box equipped with a wheel that, when turned as described below, terminated the shock to both rats. The other rat (IS) was in a box in which the wheel could not be turned. Each session consisted of 100 trials with an average ITI of $60 \mathrm{~s}$ and a shock intensity of $1.0 \mathrm{~mA}$. Shocks began simultaneously for each rat in a pair and terminated for both rats when the escape requirement was met by the ES rat. The following procedure was used to insure that the ES rat had to learn an operant response to terminate the shock. Initially the shock was terminated by a one-quarter turn of the wheel. The response requirement was increased by a one-quarter turn when each of three consecutive trials was completed in less than $5 \mathrm{~s}$. Subsequent latencies under $5 \mathrm{~s}$ increased the requirement by $50 \%$ up to a maximum of four full turns. The requirement was reduced if the trial was not completed in less than $5 \mathrm{~s}$. If the requirement was not reached in less than $30 \mathrm{~s}$, the shock was terminated and the requirement was reduced to one-quarter turn of the wheel.

\section{HPLC}

Dialysates were analyzed within 2 weeks of collection. DA and 5-HT in the dialysates were determined simultaneously using a BAS LC-4C Amperometric detector with a Unijet glassy carbon electrode directly connected to an ODS microbore column $\left(\mathrm{C}_{18}, 3 \mu \mathrm{m}, 100 \times 1 \mathrm{~mm}\right)$. The oxidation potential was $0.650 \mathrm{~V}$ relative to an $\mathrm{Ag} / \mathrm{AgCl}$ reference electrode. The mobile phase was $0.09 \mathrm{M}$ citric acid, $0.07 \mathrm{M}$ sodium phosphate, $0.10 \mathrm{mM}$ ethylenediamine tetraacetic acid, $2.62 \mathrm{mM}$ octane sulfonic acid, $10 \mathrm{mM}$ sodium chloride, and $12 \%$ methanol (pH 3.62). Data acquisition and measurement of peak heights were performed using BAS Chromgraph software. Quantitative comparisons were made with external standards that were run each day. Detection limits for DA \& 5-HT are approximately 1.7 and $1.0 \mathrm{fmol}$, respectively.

\section{Probe Verification}

To verify probe placement, rats were anesthetized with $65 \mathrm{mg} / \mathrm{kg}$ sodium pentobarbital. The brains were removed, snap frozen in isopentane, and cryostat sectioned $(40 \mu \mathrm{m})$ at $-20^{\circ} \mathrm{C}$. Sections were mounted on gelatin-treated slides, stained with cresyl violet, and coverslipped. Rats with probe placements outside of the MPFC were excluded from the

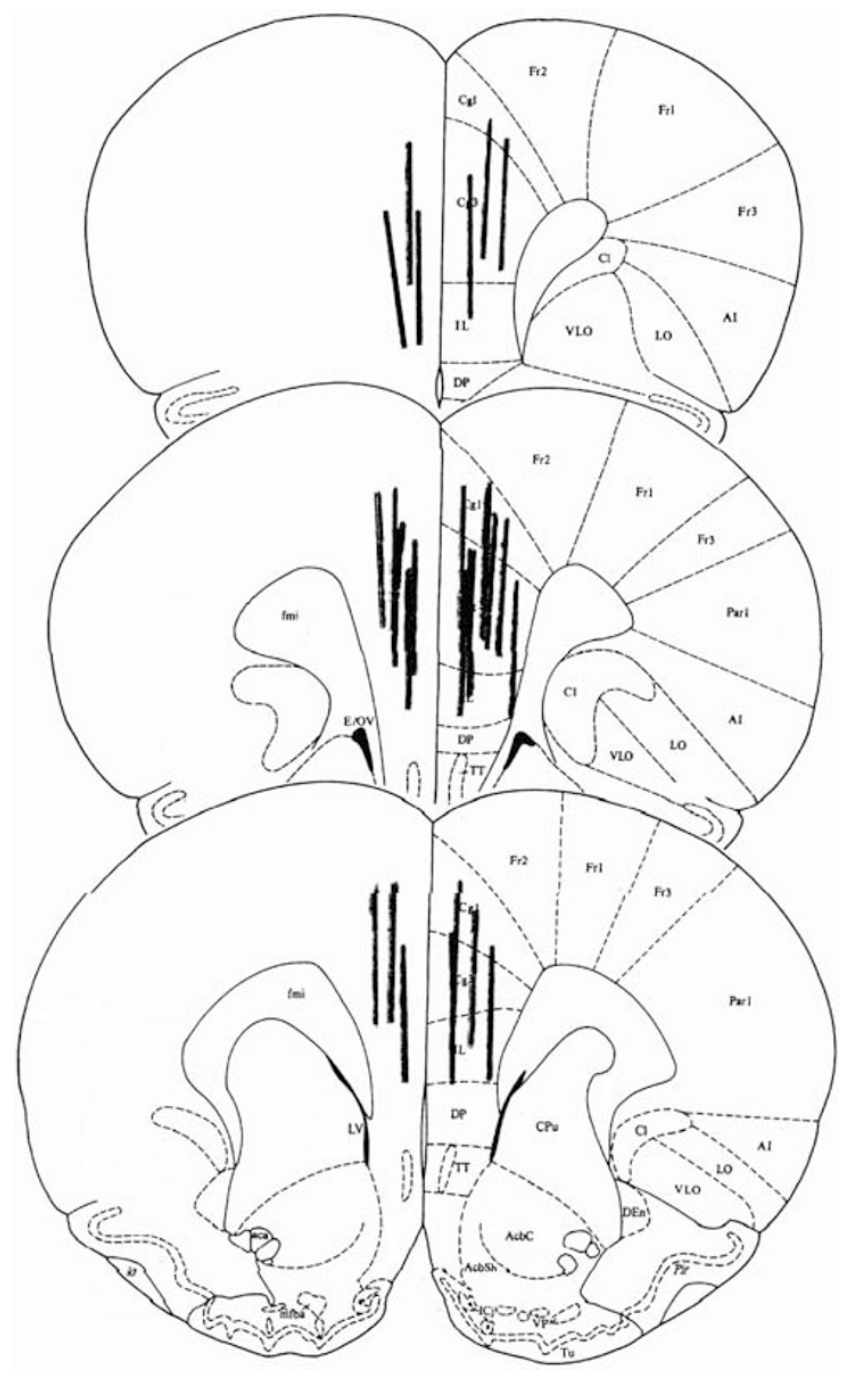

Figure I Placement of microdialysis probes in the mPFC.

analysis. Figure 1 shows probe placements of rats included in the analysis.

\section{Experimental Design and Data Analysis}

For the analysis of treatment effects, data were normalized as a percent of basal levels consisting of the mean of the first three samples. Data were analyzed using mixed ANOVA with Group as the between variable and Time as a repeated measure. Alpha was set at 0.05 for all effects. Tukey/Kramer tests were used for post hoc analyses. For the analysis of basal levels, data were expressed as absolute values.

\section{RESULTS}

\section{Basal Levels of 5-HT and DA}

Table 1 shows basal levels of 5-HT and DA on Days 1 and 2. Basal values represent the mean of the first three samples and are not corrected for recovery. For 5-HT, there was no significant effect of Group, $\mathrm{F}(2,20)=1.06, p=0.366$, and there was no interaction $\mathrm{F}(2,20)=2.633, p=097$. For DA, there was no significant effect of Group, $F(2,25)=1.59$, 
Table I Basal Levels of Serotonin and Dopamine in the mPFC

\begin{tabular}{lcclcc}
\hline & \multicolumn{2}{c}{ Serotonin } & & \multicolumn{2}{c}{ Dopamine } \\
\cline { 2 - 3 } \cline { 6 - 6 } & Day I & Day 2 & & Day I & Day 2 \\
\hline IS & $0.051(0.018)$ & $0.047(0.019)$ & & $0.076(0.020)$ & $0.117(0.029)$ \\
ES & $0.053(0.021)$ & $0.023(0.006)$ & & $0.107(0.026)$ & $0.177(0.060)$ \\
NS & $0.041(0.016)$ & $0.087(0.015)$ & & $0.160(0.046)$ & $0.212(0.043)$ \\
\hline
\end{tabular}

Three basal dialysate samples were taken prior to IS, ES, or NS treatment on day I and prior to morphine administration on day 2. Values are means ( \pm SEM) of six to eight rats and are expressed as $\mathrm{pg} / \mu \mathrm{l}$. There were no differences between groups or between day I and day 2 levels of serotonin or dopamine.

$p=0.225$, and there was no interaction $\mathrm{F}(2,25)=0.090$, $p=0.912$.

\section{5-HT and DA Efflux in the mPFC During IS, ES, or NS}

5-HT efflux increased significantly during IS compared to ES and NS (Figure 2). This was demonstrated by a significant main effect of Group, $\mathrm{F}(2,20)=13.73, p<0.01$. Post hoc tests indicated that IS was different from ES and NS, and no other group differences were found. There was a significant main effect of Time, $\mathrm{F}(12,240)=6.46, p<0.01$, reflecting an increase in 5-HT during stress. This increase was greatest in IS rats, indicated by a significant Group$\times$ Time interaction, $F(24,240)=2.41, p<0.01$. Simple effects tests indicated that IS was different from ES and NS at 40,60 , and $80 \mathrm{~min}$, and from NS at 100 and $120 \mathrm{~min}$, all $p<0.05$. There were no significant effects of Hemisphere on 5-HT efflux (data not shown).

DA efflux increased significantly during IS compared to ES and NS (Figure 3). This was demonstrated by a significant main effect of Group, $\mathrm{F}(2,20)=10.33, p<0.01$. Post hoc tests indicated that IS was different from ES and NS, and no other group differences were found. There was a significant main effect of Time, $\mathrm{F}(12,240)=3.32, p<0.01$, reflecting an increase in DA during stress. This increase was greatest in IS rats, indicated by a significant Group $\times$ Time interaction, $F(24,240)=3.31, p<0.01$. Simple effects tests indicated that IS was different from ES and NS at 40,60, 80, 100,140 , and $160 \mathrm{~min}$, all $p<0.05$. There were no significant effects of Hemisphere on DA efflux (data not shown).

\section{5-HT and DA Efflux During Morphine or Saline Administration $24 \mathrm{~h}$ After IS, ES, or NS}

There was no significant Group difference in 5-HT efflux between saline-treated rats after prior IS, ES, or NS, $\mathrm{F}(2,4)=0.031, p=0.97$, and no Group $\times$ Time interaction, $\mathrm{F}(22,44)=0.452, p=0.98$, so the data from these groups were pooled and labeled SAL. 5-HT efflux increased significantly after morphine administration in the IS-M group compared to ES-M, NS-M, and SAL (Figure 4). This was demonstrated by a significant main effect of Group, $\mathrm{F}(3,23)=11.76, p<0.01$. Post hoc tests indicated that IS-M was different from ES-M, NS-M, and SAL, and no other group differences were found. There was a significant main effect of Time, $F(11,253)=3.08, p<0.01$, reflecting an increase in 5-HT after morphine administration. This increase was greatest in the IS-M group, indicated by a significant Group $\times$ Time interaction, $F(33,253)=2.15$,

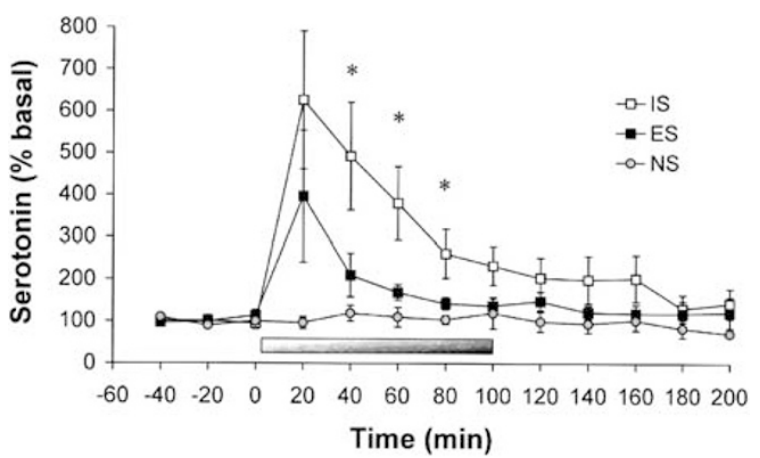

Figure 2 5-HT efflux (expressed as a percentage of baseline) in the $\mathrm{mPFC}$ before, during, and after exposure to IS, ES, or NS. The bar indicates the duration of the stress session. Exposure to IS selectively increased 5-HT efflux in the mPFC during the stress session. Data are means \pm SEM for nine rats per group. *IS significantly different from ES and NS at this time point, $p<0.05$

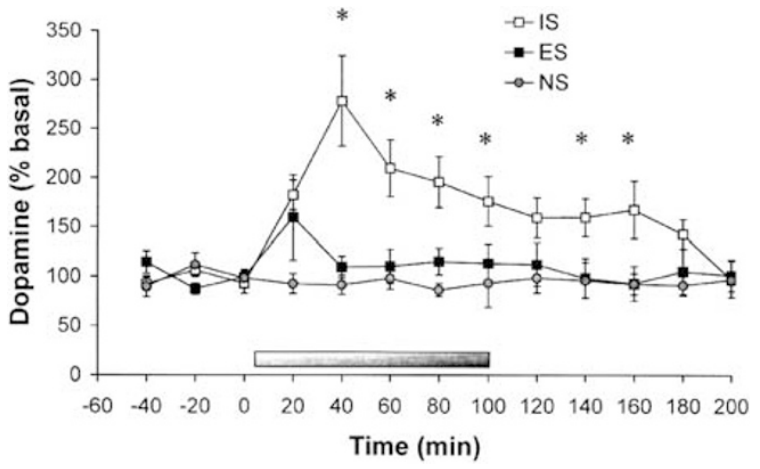

Figure 3 DA efflux (expressed as a percentage of baseline) in the mPFC before, during, and after exposure to IS, ES, or NS. The bar indicates the duration of the stress session. Exposure to IS selectively increases DA efflux in the mPFC during the stress session, and this increase persisted after the stress session terminated. Data are means \pm SEM for nine rats per group. *IS significantly different from ES and NS at this time point, $p<0.05$.

$p<0.01$. Simple effects tests indicated that IS-M was different from ES-M, NS-M, and SAL at $40,60,80,160$, and $180 \mathrm{~min}, p<0.05$. There were no significant effects of Hemisphere on 5-HT efflux (data not shown).

There was no significant Group difference in DA efflux between saline-treated rats after prior IS, ES, or NS, $\mathrm{F}(2,4)=228, p=0.81$, and no Group $\times$ Time interaction, $\mathrm{F}(22,44)=1.24, p=0.27$, so the data from these groups were pooled and labeled SAL. There was no significant group difference in DA efflux (Figure 5), $\mathrm{F}(3,25)=2.85, p>0.05$. There was a significant main effect of Time, $\mathrm{F}(11,275)=2.14, p<0.05$. Post hoc tests indicated that this reflected an increase in DA at 120 min compared to basal levels. There was no significant Group $\times$ Time interaction, $\mathrm{F}(33,275)=0.90, p>0.05$. There were no significant effects of Hemisphere on DA efflux (data not shown).

\section{DISCUSSION}

This study examined extracellular levels of 5-HT and DA in the $\mathrm{mPFC}$ during IS, ES, or NS and during a subsequent morphine or saline challenge. Large increases in 5-HT and DA efflux were observed in the mPFC of rats during and 


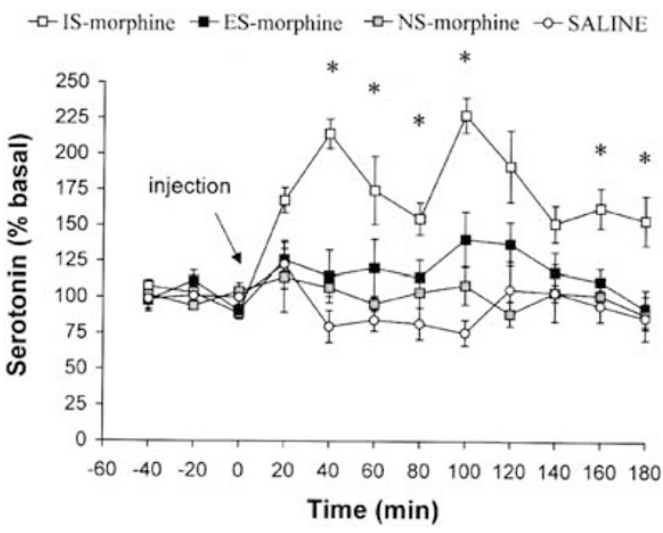

Figure 4 5-HT efflux (expressed as a percentage of baseline) in the $\mathrm{mPFC}$ during a morphine $(3 \mathrm{mg} / \mathrm{kg})$ or saline challenge (indicated by the arrow) $24 \mathrm{~h}$ after exposure to IS, ES, or NS. There was no difference between IS, ES, or NS groups for saline so their data were pooled. Previous exposure to IS selectively increased morphine-induced 5-HT efflux in the mPFC. Data are means \pm SEM for six to eight rats. *IS-M significantly different from ES-M, NS-M, and Saline at this time point, $p<0.05$.

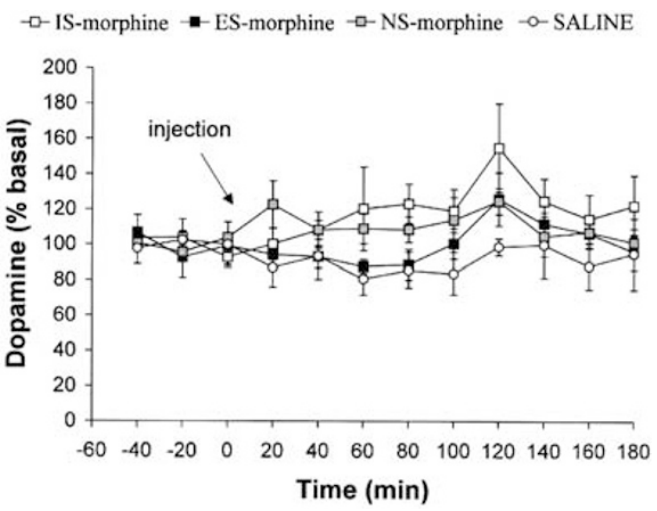

Figure 5 DA efflux (expressed as a percentage of baseline) in the mPFC during a morphine $(3 \mathrm{mg} / \mathrm{kg}$ ) or saline challenge (indicated by the arrow) $24 \mathrm{~h}$ after exposure to IS, ES, or NS. Neither exposure to IS nor morphine affected morphine-induced DA efflux in the mPFC. Data are means \pm SEM for six to eight rats.

after IS but not equal amounts of ES. We observed transient increases in 5-HT and DA efflux during ES that were similar to those observed in the mPFC during restraint stress (Matuszewich et al, 2002); however, these increases were not significantly different from NS controls. In addition, sustained increases in 5-HT efflux were observed after a morphine challenge in rats that had been exposed to IS $24 \mathrm{~h}$ previously, but not in other groups.

The finding of IS selective increases in 5-HT during stressor exposure is in agreement with the results of studies showing IS selective increases in 5-HT efflux in the DRN (Amat et al, 2001; Maswood et al, 1998) and in the amygdala, a projection region of the DRN (Amat et al, 1998a). It is important to note that there is reciprocal innervation between the MPFC and the DRN (Hajos et al, 1998). Thus, the mPFC not only receives 5 -HT projections from the DRN, it also sends glutamatergic projections to the DRN, where they synapse on GABA interneurons (Hajos et al, 1998). Activation of the mPFC thus inhibits DRN 5-HT neurons by increasing GABAergic inhibition (Celada et al, $2001)$. It has been proposed that the MPFC is an important component of a $5-\mathrm{HT} 1_{\mathrm{a}}$ receptor-mediated feedback loop (Hajos et al, 1999), and it is possible that the increases in 5HT efflux found in the present study act to inhibit the mPFC and result in disinhibition of the DRN.

However, it is unclear whether the net effect of 5-HT in the mPFC is excitatory or inhibitory. 5-HT has been reported to inhibit unit firing via a $5-\mathrm{HT}_{3}$ receptormediated process (Ashby et al, 1991). In addition, 5-HT activates GABAergic interneurons in the mPFC via $5-\mathrm{HT}_{2}$ receptors (Abi-Saab et al, 1999). However, 5-HT2 ${ }_{\mathrm{a}}$ receptors are expressed on both interneurons and pyramidal neurons in the mPFC (Willins et al, 1997). Indeed, 5-HT can exert an excitatory effect, as evidenced by increases in excitatory postsynaptic currents in layer $\mathrm{V}$ pyramidal neurons (Marek and Aghajanian, 1999).

At a behavioral level, 5- $\mathrm{HT}$ in the $\mathrm{mPFC}$ has been implicated in stress-related anxiety and fear. 5-HT efflux is increased in the mPFC in the elevated-plus maze (Rex et al, 1993), a test of anxiety, as well as during conditioned fear (Hashimoto et al, 1999). It has been argued that uncontrollable stress produces anxiety but that controllable stress does not (Maier, 1993). This may relate to the large increases in extracellular 5-HT produced by IS.

To the best of our knowledge, the present findings are the first to assess stressor controllability effects on mPFC DA using in vivo microdialysis. DA efflux in the $\mathrm{MPFC}$ has long been known to be responsive to stress (Thierry et al, 1976). DA efflux in the mPFC is increased during exposure to a wide variety of stressors including footshock (Sorg and Kalivas, 1993; Yoshioka et al, 1996), tail pinch (Finlay et al, 1995), cat odor (Sullivan and Gratton, 1998), and novelty (Davis et al, 1994). Even very mild stressors such as handling (Kawahara et al, 1999) can induce activation of mPFC DA. DA in the mPFC has previously been shown to be sensitive to stressor controllability in an ex vivo preparation (Carlson et al, 1993). In that study, uncontrollable but not controllable footshock caused a depletion of DA content in the mPFC (Carlson et al, 1993), consistent with the conclusion that uncontrollable stress selectively increases DA activity in the MPFC. It is interesting to note that stress-induced increases in MPFC DA turnover were attenuated by lesions of the amygdala (Davis et al, 1994), a region known to be preferentially affected by IS but not ES (Amat et al, 1998a). The present results are also consistent with the finding that allowing organisms to engage in nonescape 'coping behaviors' such as chewing inedible objects during exposure to stress reduces mPFC DA activity (Berridge et al, 1999). Thus, it may be that a broad class of coping behaviors that attenuate the impact of stress also reduce the $\mathrm{mPFC} D A$ response to stress. Indeed, it may be that the effectiveness of escape and other coping responses to blunt the sequelae of stress depend on their ability to reduce the $\mathrm{mPFC}$ response to stress.

DA appears to be generally inhibitory with regard to mPFC function. One model of mPFC function, formulated by Goldman-Rakic, posits that activation of D1 receptors on GABA interneurons in the mPFC inhibits descending glutamatergic neurons (Goldman-Rakic et al, 2000). Behavioral studies have supported an inhibitory role for DA in the mPFC. For example, DA in the mPFC serves to inhibit locomotor activity, and this inhibition is due to its action at the D1 receptor (Vezina et al, 1991). Additional support for 
an inhibitory role for DA includes the finding that DA depletion in the $\mathrm{mPFC}$ induces motor hyperactivity (Espejo and Minano, 1999) and reduces immobility during swimming (Doherty and Gratton, 1996). Activation of DA release in the $\mathrm{mPFC}$ during uncontrollable stress may result in inhibition of the MPFC and thus a decrease in mPFCmediated behaviors. Coping behaviors, including escape, may therefore function by decreasing this inhibition.

With regard to responses to morphine, 5-HT levels in the mPFC significantly increased only in subjects that had received IS $24 \mathrm{~h}$ earlier. Although 5-HT levels following morphine were slightly elevated in subjects that had received ES and NS, this increase was not statistically significant. This potentiation of the 5-HT response to morphine is likely due to IS-induced sensitization of 5-HT neurons in the DRN, and a consequent potentiation of morphine activation of 5-HT neurons in the DRN. There is evidence that morphine activates the DRN by disinhibiting 5-HT neurons (Jolas and Aghajanian, 1997). This disinhibition may be mediated by inhibitory GABA interneurons that synapse on 5-HT neurons in the DRN (Wang et al, 1992) and express $\mu$ opioid receptor mRNA (Mansour et al, 1994). Opioids acting on $\mu$ receptors inhibit these GABA interneurons (Wang and Nakai, 1993), resulting in a disinhibition of 5-HT neurons in the DRN. Consistent with an action of morphine on DRN 5-HT neurons, increases in extracellular 5-HT have been observed in projection regions of the DRN after systemic or intra-raphe injections of morphine (Tao and Auerbach, 1994). If IS results in a downregulation of $5 \mathrm{HT}_{\mathrm{a}}$ autoreceptors, then activation of DRN 5-HT neurons by morphine in subjects that have been exposed to IS should result in a potentiated 5-HT response. This sort of potentiation has been shown to occur in the basolateral amygdala when rats are subjected to a mild stressor $24 \mathrm{~h}$ after IS (Amat et al, 1998a,b). Clearly, the present results are consistent with the hypothesis that IS sensitizes DRN 5-HT neurons.

As already noted, an increase in 5-HT efflux in response to morphine in ES and NS rats was not observed. This is not surprising given the low dose of morphine used in the present study. Morphine is known to activate DRN serotonergic neurons, but has only been shown to increase 5-HT efflux in the mPFC at high doses. 5-HT efflux increases significantly after doses of 10 and $20 \mathrm{mg} / \mathrm{kg}$, but not after $5 \mathrm{mg} / \mathrm{kg}$ (Tao and Auerbach, 1994). It is interesting to note that in the Tao and Auerbach study, 5-HT levels peaked at $90 \mathrm{~min}$. In the present study, 5-HT efflux after morphine in IS rats appeared to peak at two time points: an early peak at $40 \mathrm{~min}$ and a later peak at $100 \mathrm{~min}$. There was no increase in 5-HT in IS rats subjected to saline injections, so it is not likely that the early increase was due to injection stress. Thus, it is possible that IS sensitization of DRN 5-HT neurons resulted in a response to a subthreshold dose of morphine that was potentiated both temporally and in magnitude.

We did not observe an increase in DA efflux in any of the groups after $3 \mathrm{mg} / \mathrm{kg}$ morphine. Although it is known that morphine increases DA efflux in the NAc (Pothos et al, 1991; Rada et al, 1991), it has previously been demonstrated that morphine has no effect on DA efflux in the mPFC (Bassareo et al, 1996; Devoto et al, 2002). However, one group has shown that acute morphine at a dose similar to that used in the present study increased the DOPAC/DA ratio in the $\mathrm{mPFC}$ in an ex vivo preparation (Vezina et al, 1992). However, the absence of DA increases in the present study suggests that the potentiation of morphine CPP and psychomotor responses produced by prior IS cannot be attributed to 5-HT potentiation of DA response in the $\mathrm{mPFC}$. It is still possible that such an interaction might occur in the NAc.

The present results add to prior results indicating that 5$\mathrm{HT}$ efflux in projection regions of the DRN is sensitive to stressor controllability. Given the involvement of the mPFC in cognitive functions including the planning and execution of complex tasks (Fuster, 1997), as well as in psychiatric disorders (Drevets et al, 1998), the regulation of 5-HT in this structure may be of special importance. In addition, the present results offer the first demonstration that stressor controllability modulates the subsequent neurochemical response to morphine. Thus, these results reflect the occurrence of stressor controllability-modulated neural sensitization, and this process may be critical for the occurrence of the persistent trans-situational sensitization of behavioral responses to morphine that is produced by uncontrollable stress.

\section{ACKNOWLEDGEMENTS}

This research was supported by NIH grants MH50479 and DA13159 (SFM) and by the Undergraduate Research Opportunities Program of the University of Colorado (DH).

\section{REFERENCES}

Abi-Saab WM, Bubser M, Roth RH, Deutch AY (1999). 5-HT2 receptor regulation of extracellular GABA levels in the prefrontal cortex. Neuropsychopharmacology 20: 92-96.

Amat J, Matus-Amat P, Watkins LR, Maier SF (1998a). Escapable and inescapable stress differentially alter extracellular levels of 5$\mathrm{HT}$ in the basolateral amygdala of the rat. Brain Res 812: 113120.

Amat J, Matus-Amat P, Watkins LR, Maier SF (1998b). Escapable and inescapable stress differentially and selectively alter extracellular levels of 5-HT in the ventral hippocampus and dorsal periaqueductal gray of the rat. Brain Res 797: 12-22.

Amat J, Sparks PD, Matus-Amat P, Griggs J, Watkins LR, Maier SF (2001). The role of the habenular complex in the elevation of dorsal raphe nucleus serotonin and the changes in the behavioral responses produced by uncontrollable stress. Brain Res 917: 118-126.

Ashby Jr CR, Minabe Y, Edwards E, Wang RY (1991). 5-HT3-like receptors in the rat medial prefrontal cortex: an electrophysiological study. Brain Res 550: 181-191.

Bassareo V, Tanda G, Petromilli P, Giua C, Di Chiara G (1996). Non-psychostimulant drugs of abuse and anxiogenic drugs activate with differential selectivity dopamine transmission in the nucleus accumbens and in the medial prefrontal cortex of the rat. Psychopharmacology (Berl) 124: 293-299.

Berridge CW, Mitton E, Clark W, Roth RH (1999). Engagement in a non-escape (displacement) behavior elicits a selective and lateralized suppression of frontal cortical dopaminergic utilization in stress. Synapse 32: 187-197.

Carlson JN, Fitzgerald LW, Keller Jr RW, Glick SD (1993). Lateralized changes in prefrontal cortical dopamine activity induced by controllable and uncontrollable stress in the rat. Brain Res 630: 178-187. 
Celada P, Puig MV, Casanovas JM, Guillazo G, Artigas F (2001). Control of dorsal raphe serotonergic neurons by the medial prefrontal cortex: involvement of serotonin-1A, GABA(A), and glutamate receptors. J Neurosci 21: 9917-9929.

Davis M, Hitchcock JM, Bowers MB, Berridge CW, Melia KR, Roth RH (1994). Stress-induced activation of prefrontal cortex dopamine turnover: blockade by lesions of the amygdala. Brain Res 664: 207-210.

Devoto P, Flore G, Pira L, Diana M, Gessa L (2002). Co-release of noradrenaline and dopamine in the prefrontal cortex after acute morphine and during morphine withdrawal. Psychopharmacology (Berl) 160: 220-224.

Doherty MD, Gratton A (1996). Medial prefrontal cortical D1 receptor modulation of the meso-accumbens dopamine response to stress: an electrochemical study in freely-behaving rats. Brain Res 715: 86-97.

Drevets WC, Ongur D, Price JL (1998). Neuroimaging abnormalities in the subgenual prefrontal cortex: implications for the pathophysiology of familial mood disorders. Mol Psychiatry 3: 220-226.

Espejo EF, Minano FJ (1999). Prefrontocortical dopamine depletion induces antidepressant-like effects in rats and alters the profile of desipramine during Porsolt's test. Neuroscience 88: 609-615.

Finlay JM, Zigmond MJ, Abercrombie ED (1995). Increased dopamine and norepinephrine release in medial prefrontal cortex induced by acute and chronic stress: effects of diazepam. Neuroscience 64: 619-628.

Fuster JM (1997). Network memory. Trends Neurosci 20: 451-459. Goeders NE, Guerin GF (1994). Non-contingent electric footshock facilitates the acquisition of intravenous cocaine self-administration in rats. Psychopharmacology (Berl) 114: 63-70.

Goldman-Rakic PS, Muly 3rd EC, Williams GV (2000). D(1) receptors in prefrontal cells and circuits. Brain Res Brain Res Rev 31: 295-301.

Grahn RE, Will MJ, Hammack SE, Maswood S, McQueen MB, Watkins LR et al (1999). Activation of serotonin-immunoreactive cells in the dorsal raphe nucleus in rats exposed to an uncontrollable stressor. Brain Res 826: 35-43.

Hajos M, Hajos-Korcsok E, Sharp T (1999). Role of the medial prefrontal cortex in 5-HT1A receptor-induced inhibition of 5HT neuronal activity in the rat. Br J Pharmacol 126: 1741-1750.

Hajos M, Richards CD, Szekely AD, Sharp T (1998). An electrophysiological and neuroanatomical study of the medial prefrontal cortical projection to the midbrain raphe nuclei in the rat. Neuroscience 87: 95-108.

Hashimoto S, Inoue T, Koyama T (1999). Effects of conditioned fear stress on serotonin neurotransmission and freezing behavior in rats. Eur J Pharmacol 378: 23-30.

Jolas T, Aghajanian GK (1997). Opioids suppress spontaneous and NMDA-induced inhibitory postsynaptic currents in the dorsal raphe nucleus of the rat in vitro. Brain Res 755: 229-245.

Kawahara Y, Kawahara H, Westerink BH (1999). Comparison of effects of hypotension and handling stress on the release of noradrenaline and dopamine in the locus coeruleus and medial prefrontal cortex of the rat. Naunyn Schmiedebergs Arch Pharmacol 360: 42-49.

Maier SF (1993). Learned Helplessness, Fear, and Anxiety. Academic Press: New York.

Maier SF, Grahn RE, Watkins LR (1995). 8-OH-DPAT microinjected in the region of the dorsal raphe nucleus blocks and reverses the enhancement of fear conditioning and interference with escape produced by exposure to inescapable shock. Behav Neurosci 109: 404-412.

Maier SF, Seligman ME (1976). Learned helplessness: theory and evidence. Journal of Experimental Psychology: General 105: 3-46.

Mansour A, Fox CA, Thompson RC, Akil H, Watson SJ (1994). muOpioid receptor mRNA expression in the rat CNS: comparison to mu-receptor binding. Brain Res 643: 245-265.
Marek GJ, Aghajanian GK (1999). 5-HT2A receptor or alpha1adrenoceptor activation induces excitatory postsynaptic currents in layer V pyramidal cells of the medial prefrontal cortex. Eur J Pharmacol 367: 197-206.

Maswood S, Barter JE, Watkins LR, Maier SF (1998). Exposure to inescapable but not escapable shock increases extracellular levels of 5-HT in the dorsal raphe nucleus of the rat. Brain Res 783: 115-120.

Matuszewich L, Filon ME, Finn DA, Yamamoto BK (2002). Altered forebrain neurotransmitter responses to immobilization stress following 3,4-methylenedioxymethamphetamine. Neuroscience 110: $41-48$.

Minor TR, Dess NK, Ben-David E, Chang WC (1994). Individual differences in vulnerability to inescapable shock in rats. $J$ Exp Psychol Anim Behav Process 20: 402-412.

NIDA (2002). Coping with stress subject of new NIDA community alert. NIDA Notes 17. www.drugabuse.gov/NIDA-Notes/NNIndex.html.

Paxinos G, Watson C (1998). The Rat Brain in Stereotaxic Coordinates, 4th edn Academic Press:New York.

Piazza PV, Le Moal M (1998). The role of stress in drug selfadministration. Trends Pharmacol Sci 19: 67-74.

Pothos E, Rada P, Mark GP, Hoebel BG (1991). Dopamine microdialysis in the nucleus accumbens during acute and chronic morphine, naloxone-precipitated withdrawal and clonidine treatment. Brain Res 566: 348-350.

Rada P, Mark GP, Pothos E, Hoebel BG (1991). Systemic morphine simultaneously decreases extracellular acetylcholine and increases dopamine in the nucleus accumbens of freely moving rats. Neuropharmacology 30: 1133-1136.

Rasmusson AM, Goldstein LE, Deutch AY, Bunney BS, Roth RH (1994). 5-HT1a agonist +/-8-OH-DPAT modulates basal and stress-induced changes in medial prefrontal cortical dopamine. Synapse 18: 218-224.

Rebec GV, Curtis SD (1983). Reciprocal changes in the firing rate of neostriatal and dorsal raphe neurons following local infusions or systemic injections of D-amphetamine: evidence for neostriatal heterogeneity. J Neurosci 3: 2240-2250.

Rex A, Marsden CA, Fink H (1993). Effect of diazepam on cortical 5-HT release and behaviour in the guinea-pig on exposure to the elevated plus maze. Psychopharmacology (Berl) 110: 490-496.

Robinson TE, Kolb B (1999). Morphine alters the structure of neurons in the nucleus accumbens and neocortex of rats. Synapse 33: 160-162.

Shaham Y, Rajabi H, Stewart J (1996). Relapse to heroin-seeking in rats under opioid maintenance: the effects of stress, heroin priming, and withdrawal. J Neurosci 16: 1957-1963.

Shaham Y, Stewart J (1994). Exposure to mild stress enhances the reinforcing efficacy of intravenous heroin self-administration in rats. Psychopharmacology (Berl) 114: 523-527.

Shaham Y, Stewart J (1995). Stress reinstates heroin-seeking in drug-free animals: an effect mimicking heroin, not withdrawal. Psychopharmacology (Berl) 119: 334-341.

Shalev U, Highfield D, Yap J, Shaham Y (2000). Stress and relapse to drug seeking in rats: studies on the generality of the effect. Psychopharmacology (Berl) 150: 337-346.

Short KR (1997). Inescapable stress, a benzodiazepine inverse agonist, and serotonin in dorsal raphe increases anxiety and decreases 5-HT1A receptor binding in rat dorsal raphe. Soci Neurosci Abstr 23: 1078.

Short KR, Maier SF (1993). Stressor controllability, social interaction, and benzodiazepine systems. Pharmacol Biochem Behav 45: 827-835.

Sorg BA, Kalivas PW (1993). Effects of cocaine and footshock stress on extracellular dopamine levels in the medial prefrontal cortex. Neuroscience 53: 695-703.

Sotelo C, Cholley B, El Mestikawy S, Gozlan H, Hamon M (1990). Direct immunohistochemical evidence of the existence of 5- 
Stressor controllability modulates stress-induced dopamine

ST Bland et al

1596

HT1A autoreceptors on serotoninergic neurons in the midbrain rape nuclei. Eur J Neurosci 2: 1144-1154.

Sullivan RM, Gratton A (1998). Relationships between stressinduced increases in medial prefrontal cortical dopamine and plasma corticosterone levels in rats: role of cerebral laterality. Neuroscience 83: 81-91.

Tao R, Auerbach SB (1994). Increased extracellular serotonin in rat brain after systemic or intraraphe administration of morphine. $J$ Neurochem 63: 517-524.

Thierry AM, Tessin JP, Blanc G, Glowinski J (1976). Selective activation of mesocortical DA system by stress. Nature 263: 242244.

Tzschentke TM, Schmidt WJ (1999). Functional heterogeneity of the rat medial prefrontal cortex: effects of discrete subareaspecific lesions on drug-induced conditioned place preference and behavioural sensitization. Eur J Neurosci 11: 4099-4109.

Vezina P, Blanc G, Glowinski J, Tessin JP (1991). Opposed behavioural outputs of increased dopamine transmission in prefrontocortical and subcortical areas: a role for the cortical D1 dopamine receptor. Eur J Neurosci 3: 1001-1007.

Vezina P, Blanc G, Glowinski J, Tessin JP (1992). Nicotine and morphine differentially activate brain dopamine in prefronto- cortical and subcortical terminal fields: effects of acute and repeated injections. J Pharmacol Exp The 261: 484-490.

Wang QP, Nakai Y (1993). Enkephalinergic innervation of GABAergic neurons in the dorsal rape nucleus of the rat. Brain Res Bull 32: 315-320.

Wang QP, Ochiai H, Nakai Y (1992). GABAergic innervation of serotonergic neurons in the dorsal rape nucleus of the rat studied by electron microscopy double immunostaining. Brain Res Bull 29: 943-948.

Will MJ, Der-Avakian A, Pepin JL, Durkan BT, Watkins LR, Maier SF (2002). Modulation of the locomotor properties of morphine and amphetamine by uncontrollable stress. Pharmacol Biochem Behav 71: 345-351.

Will MJ, Watkins LR, Maier SF (1998). Uncontrollable stress potentiates morphine's rewarding properties. Pharmacol Biochem Behav 60: 655-664.

Willing DL, Dutch AY, Roth BL (1997). Serotonin 5-HT2A receptors are expressed on pyramidal cells and interneurons in the rat cortex. Synapse 27: 79-82.

Yoshioka M, Matsumoto M, Togashi H, Saito H (1996). Effect of conditioned fear stress on dopamine release in the rat prefrontal cortex. Neurosci Lett 209: 201-203.

Neuropsychopharmacology 